\title{
Complete genome sequencing of Peyer's patches-derived Lactobacillus taiwanensis CLG01, a potential probiotic with antibacterial and immunomodulatory activity
}

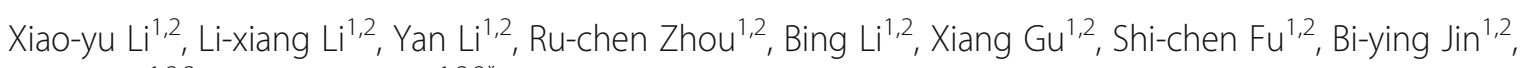
Xiu-li Zuo ${ }^{1,2,3}$ and Yan-qing $\mathrm{Li}^{1,2,3^{*}}$

\begin{abstract}
Background: The genus Lactobacillus is an important component of the gastrointestinal tract of human and animals and commonly considered as probiotic. L. taiwanensis has long been proposed to be a probiotic whereas understanding on this species is still in its infancy. Genomic information of L. taiwanensis is fairly limited. Extensive characterization of its beneficial traits is needed.
\end{abstract}

Results: A new strain CLG01 of L. taiwanensis was isolated from mouse Peyer's patches. We established its probiotic profile through in vitro experiments. Complete genome of this strain was also sequenced and analyzed. $L$. taiwanensis CLG01 showed robust tolerance to acid and a degree of tolerance to bile salt with a promising antibacterial activity against a broad spectrum of pathogenic bacteria. In vitro treatment of mouse RAW 264.7 macrophage cells with heat-killed bacteria and bacterial supernatant of L. taiwanensis CLG01 resulted in enhancement of immune responses and upregulated expression of TNF- $a$ and IL-6. The strain CLG01 also increased the IL-10 production of macrophages when co-treated with lipopolysaccharide (LPS). Complete genome of $L$. taiwanensis CLG01 contained a 1.89 Mb chromosome and two plasmids. Further genomic analysis revealed the presence of genes related to its resistance to different stresses and the beneficial effects mentioned above. Moreover, biosynthetic gene clusters (BGCs) encoding antimicrobial peptides, like bacteriocin, linear azol(in)econtaining peptide (LAP) and lanthipeptide, were also identified in the genome of L. taiwanensis CLG01.

(Continued on next page)

\footnotetext{
*Correspondence: liyanqing@sdu.edu.cn

${ }^{1}$ Department of Gastroenterology, Qilu Hospital, Cheeloo College of

Medicine, Shandong University, 107 Wenhuaxi Road, Jinan 250012,

Shandong Province, China

${ }^{2}$ Laboratory of Translational Gastroenterology, Qilu Hospital, Cheeloo College of Medicine, Shandong University, Jinan, Shandong, China

Full list of author information is available at the end of the article
} 
(Continued from previous page)

Conclusions: L. taiwanensis CLG01, isolated from mouse Peyer's patches, is the first L. taiwanensis strain with both phenotypes and genotypes systematically studied. These preliminary data confirmed the role of L. taiwanensis CLG01 as a potential probiotic candidate with antibacterial and immunomodulatory activity, which provide insight for further investigation to this species.

Keywords: Lactobacillus taiwanensis, Probiotic, Antibacterial activity, Immunomodulation, Peyer's patches, complete genome

\section{Background}

Mammalian gastrointestinal tract is a nutrient-rich environment populated by diverse, highly mutualistic microbes [1]. Gut microbes and their bioactive byproducts have profound impacts on health status and gut homeostasis of the host [2]. Accumulating evidence demonstrated that abnormal host-microbial interactions could be the central or contributing cause of multiple enteral and parenteral diseases, including inflammatory bowel disease (Crohn's disease and ulcerative colitis) [3], colorectal carcinoma [4-6], neurodegenerative disorders (e.g., Parkinson's disease and Alzheimer's disease) [7, 8], metabolism disorders (e.g., obesity and type 2 diabetes) [9]. Therefore, it's imperative to maintain the balance of the interplay between gut microbiota and the host. In recent years, microbial-based strategies (e.g., probiotics, prebiotics, and fecal microbiota transplants) aiming at modulating gut microbiomes have been tested in a wide range of clinical contexts, with satisfying outcomes obtained $[10,11]$.

Probiotics are defined as "live microorganisms that, when administered in adequate amounts, confer a health benefit on the host" according to the World Health Organization (WHO) [12]. Lactic acid bacteria (LAB) are a group of Gram-positive bacteria that produce lactic acid as a major fermentation metabolite [13]. The genus Lactobacillus is the most studied LAB and specific Lactobacillus species are regarded as probiotic due to a wide range of benefits. Lactobacilli exerts beneficial effects on intestinal epithelia by direct contact with epithelial cells [14]. L. fermentum was reported to initiate signalling pathways involved in epithelial barrier protection in the mouse model of colitis [15]. Furthermore, previous studies have shown that some heat-killed Lactobacillus strains (e.g., L. rhamnosus GG, L. helveticus IMAU70129, and L. casei IMAU60214) could trigger innate immune responses and improve the phagocytic and bactericidal activities of human macrophages [16]. In addition, certain strains of $L$. helveticus and $L$. acidophilus were capable of reducing the growth of HT-29 human colon cancer cells and subsequently exert an anti-tumor effect [17]. Some types of Lactobacillus species proved to be probiotics, such as L. acidophilus, $L$. rhamnosus GG, have been commercially utilized in dairy products and bring therapeutic benefits to the host [18, 19]. Of note, the probiotic properties can be species-, dose-, and disease-specific and may not be the same as other strains of the same genus or species [20]. Consequently, searches for new probiotics and further exploitation of the existing ones are still necessary.

L. taiwanensis was originally isolated and identified by Taiwanese from silage cattle feed and showed the highest sequence homology with $L$. gasseri and L. johnsonii $[21,22]$. Previous studies have shown that $L$. taiwanensis is abundant in small intestine [23]. The BALB/c mice treated with $L$. taiwanensis display an elevated Treg cell frequency in the gut-associated lymphoid tissues [24]. Researches based on the 16S rRNA sequencing have revealed the low abundance of L. taiwanensis in colorectal cancer and cervical neoplasia, indicating that L. taiwanensis might provide protective effects in the colorectal tumorgenesis and cervical neoplasia development [25, $26]$. Kim et al. have reported that L. taiwanensis is capable of producing antimicrobial peptides and inhibiting growth of pathogenic microorganisms like Salmonella gallinarum and Streptococcus iniae [27]. These scattered examples indicate that $L$. taiwanensis possibly represent a novel probiotic species. However, few data are available to support this view. L. taiwanensis has not yet been functionally characterized. Despite the significance in predicting the structures and important capabilities of microorganisms, the current genome information of $L$. taiwanensis is fairly limited, with only one strain genetically accessible. In this study, a new strain of L. taiwanensis, named L. taiwanensis CLG01, was isolated from the Peyer's patches, the lymphoid tissues of mouse small intestine. We evaluated some basic physiological characteristics, including the ability to survive in acid and bile salt, adhesive ability, antibacterial activity, and immunomodulatory effects in vitro. By detailed analysis of the complete genome sequence of L. taiwanensis CLG01, we are allowed to combine the beneficial effects of CLG01 with its genomic features.

\section{Results}

\section{Lactobacillus isolation and identification}

A total of 9 strains were isolated with the de Man Rogosa Sharpe (MRS) agar plates from mouse Peyer's 
patches samples. All isolates were Gram-positive with rod shape under optical microscopy. On the basis of $16 \mathrm{~S}$ rRNA sequencing and analysis, the isolates were identified as L. taiwanensis $(n=1)$, L. reteuri $(n=4), L$. johnsonii $(n=3)$ and L. murinus $(n=1)$ respectively. The $L$. taiwanensis strain, named as CLG01, was selected for further investigations of physiological functions and probiotic traits. Single colony of L. taiwanensis CLG01 was distinguishable as translucent with irregular border after $48 \mathrm{~h}$ of incubation on MRS agar plate (Fig. S1). Scanning electron microscopy (SEM) image of this strain revealed a typical rod-like structure (Fig. S2).

\section{Genome features and phylogenetic analysis of $L$. taiwanensis CLG01}

To further elucidate the genomic characteristics of $L$. taiwanensis CLG01, complete genome sequencing was performed. The whole genome of $L$. taiwanensis CLG01 was composed of a $1.89 \mathrm{Mb}$ single, circular chromosome with GC content of $34.11 \%$ and two circular plasmids named as plasmid1 $(137,288 \mathrm{bp})$ and plasmid2 $(10,527$ bp). A total of 1994 genes (1771 protein-coding genes), 21 rRNA genes, and 77 tRNA genes were identified (Table 1). To unravel the phylogenetic position of the strain CLG01, a phylogenetic tree based on 295 singlecopy orthologous genes was constructed using neighborjoining method (Fig. 1). The genome-wide phylogenetic analysis of CLG01 showed the closest relatedness with $L$. taiwanensis DSM 21401. Circular genome map of L. taiwanensis CLG01 revealed the genome distribution (Fig. 2). After searching for clusters of orthologous groups (COG) database, 1680 protein-coding genes were classified functionally into 25 categories (Fig. 3, Table S1). "Function unknown" has the highest number of genes, followed by "Replication, recombination, and repair," "Translation, ribosomal structure and biogenesis" and "Transcription". Additionally, through the analysis of the whole genome by the webtool PathogenFinder,

Table 1 General genome features of L. taiwanensis CLG01

\begin{tabular}{ll}
\hline Attributes & Values \\
\hline Genome size (bp) & $1,893,948$ \\
GC content (\%) & $34.11 \%$ \\
Plasmid & 2 \\
rRNAs & \\
5S rRNA & 7 \\
16S rRNA & 7 \\
23S rRNA & 7 \\
tRNAs & 77 \\
ncRNAs & 3 \\
Protein-coding genes & 1771 \\
Pseudo genes & 122 \\
\hline
\end{tabular}

the L. taiwanensis CLG01 was predicted to be a nonhuman pathogenic microorganism.

\section{Carbohydrate metabolism of L. taiwanensis CLG01}

Among the COG-recognized genes, 132 genes involved in carbohydrate metabolism and transport with 55 genes for energy production and conversion. Moreover, 19 genes encoding proteins of phosphotransferase system (PTS), a major carbohydrate active transport system, were detected within the genome of CLG01 (Table S2). PTS in CLG01 was involved in transporting various types of sugars, including glucose, beta-glucoside, galactitol, cellobiose, lactose, mannose, fructose, sorbose, glucitol, and sorbitol. A total of 73 genes predicted carbohydrate-active enzymes (CAZymes) were identified in the L. taiwanensis CLG01 genome and divided in to 5 subgroups including 30 genes for glycosyltransferases, 24 genes for glycoside hydrolases, 8 genes for carbohydrate esterases, 8 genes for carbohydrate-binding molecules and 3 genes for auxiliary activity.

\section{Stress resistance analysis}

In the aim of characterizing the potential of L.taiwanensis CLG01 to survive in the harsh environment of gastrointestinal tract, we studied its ability to tolerant acid and bile salt in vitro. Viable cells were measured after incubation for $2 \mathrm{~h}$ in low $\mathrm{pH}$ conditions. Considerable acid tolerance was observed at both $\mathrm{pH} 3.0$ and $\mathrm{pH} 2.0$ (Fig. 4a). In detail, GLG01 could stay alive and increase beyond the initial count at $\mathrm{pH} 3.0$ and maintain a high survival rate of $93.3 \pm 4.63 \%$ at $\mathrm{pH} 2.0$. Results of bile salt tolerance were shown in Fig. 4b. The strain CLG01 exhibited a survival rate of $89.4 \pm 4.26 \%$ on the medium containing $0.1 \%$ bile salt. With the increase of ox gall sodium cholate concentration, the growth of CLG01 was gradually impaired. However, no obvious colony was observed on the MRS agar plates with the bile salt concentration of $0.3 \%$, suggesting that the bacterial growth was totally inhibited.

At molecular level, genome of CLG01 was predicted to carry the gene encoding sodium-proton antiporter which exchange sodium ions and protons across the membrane [28] and 8 genes encoding F0F1-ATP synthase which is essential to maintain intracellular $\mathrm{pH}$ homeostasis [29] (Table 2). The CLG01 harbored the gene (H1A07 00295) that encode linear amide $\mathrm{C}-\mathrm{N}$ hydrolase, which belongs to choloylglycine hydrolase family and catalyzes the de-conjugation of bile acids [30]. More stress-related proteins linked to the resistance to different types of stresses (e.g., temperature, oxidative stress) were also identified in the genome of L. taiwanensis CLG01 with detailed information listed in Table 2. 


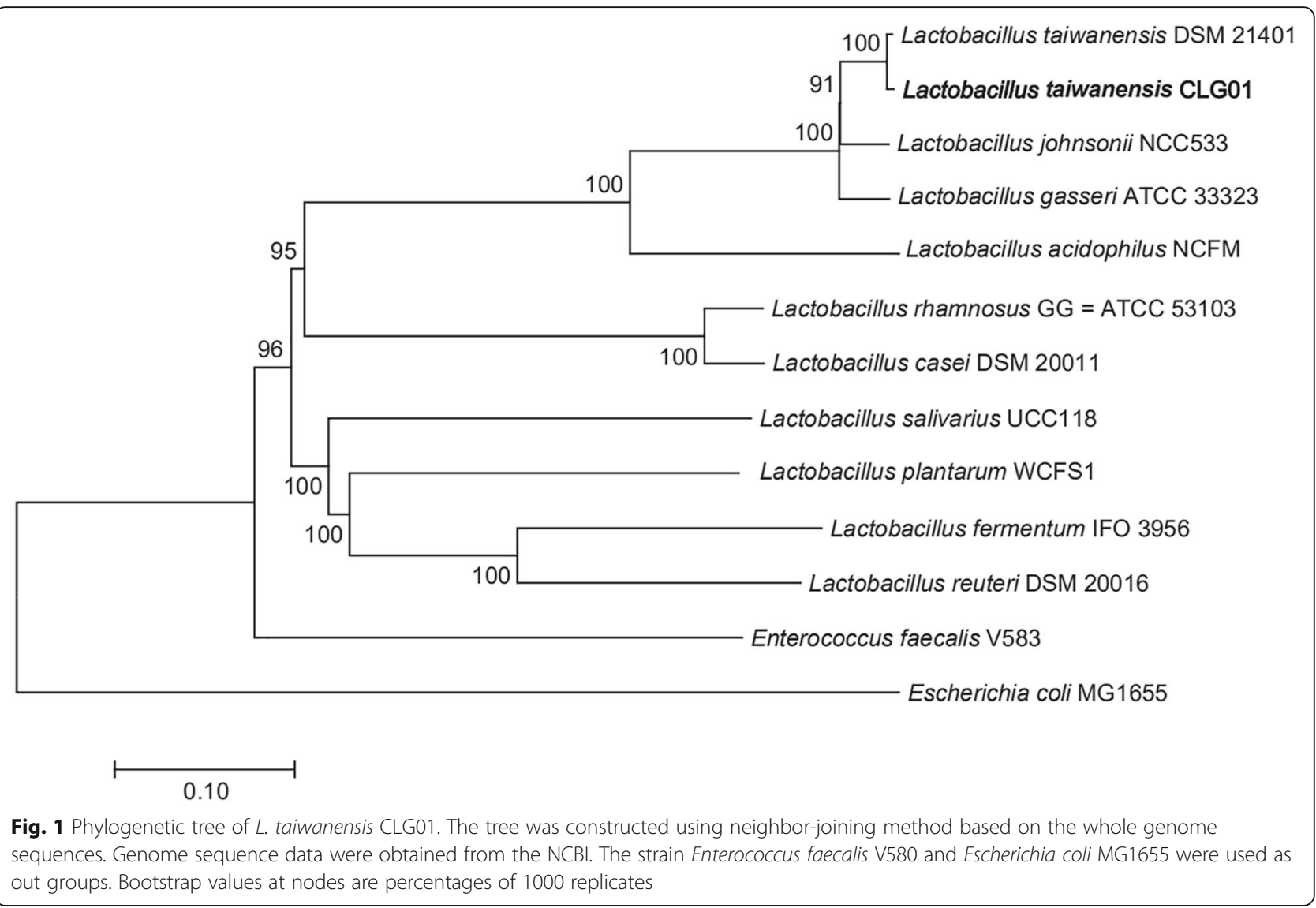

\section{Adhesive ability of $L$. taiwanensis CLG01}

Bacterial adhesive ability to host intestinal epithelium and the outer mucus layer is one of the selecting criteria for probiotics [31]. We tested the host attachment capability of L. taiwanensis CLG01 in vitro. Two kinds of human intestinal epithelial cells Caco-2 and LS $174 \mathrm{~T}$ monolayers were used. As shown in Fig. 4c, L. taiwanensis CLG01 adhered much better to LS $174 \mathrm{~T}$ cells than Caco-2 cells with two orders of magnitude difference observed $(P<0.001)$. The bioinformatic analysis results showed that the CLG01 genome encoded the cellsurface proteins that involved in adhesion such as CBS domain-containing protein (H1A07_01450 and H1A07_ 08900), elongation factor Ts (H1A07_03665), and elongation factor Tu (H1A07_05600), etc.

\section{Antibacterial activity of $L$. taiwanensis CLG01}

One of the important characteristics of probiotics is to antagonize pathogens. In this study, the antibacterial activity of $L$. taiwanensis CLG01 was evaluated by well agar diffusion method. The cell-free supernatant of L. taiwanensis CLG01 was obtained at different time points $(12 \mathrm{~h}$, $16 \mathrm{~h}$ and $20 \mathrm{~h}$ ). The diameters of inhibition zones were measured after $24 \mathrm{~h}$ incubation at $37^{\circ} \mathrm{C}$ and the results are reported in Table 3. Our results showed that the cell-free supernatant of L. taiwanensis CLG01 exhibited inhibitory effects against both Gram-positive bacteria (Staphylococcus aureus, Listeria monocytogenes and Bacillus subtilis) and Gram-negative bacteria (Escherichia coli, Salmonella typhi and Pseudomonas aeruginosa) with a digestive tropism. The strain CLG01 showed the strongest antibacterial activity (>15 mm) against Staphylococcus aureus, while the weakest result was for Listeria monocytogenes. The cell-free supernatant obtained at $16 \mathrm{~h}$ has the strongest inhibitory effect on the growth of indicator bacteria. To further determine the type of the inhibitory substances responsible for the anti-pathogen activity, the cell-free supernatant was pretreated by proteinase or proteinase inhibitor EDTA respectively. We found that proteinase pretreatment led to significant decreases of inhibition zones around the wells, whereas EDTA treatment enlarged the circle diameters (Fig. 5).

Consistent with the observed inhibitory effects of L. taiwanensis CLG01, the genome of CLG01 contained genes coding for antibacterial compounds, like bacteriocins (H1A07_02945 and H1A07_02950). Bacteriocin immunity proteins (H1A07_02990 and H1A07_03010) were identified in the genome as the self-protecting factors. Furthermore, analysis of secondary metabolites BGCs using the antiSMASH database revealed the presence of BGCs related to 


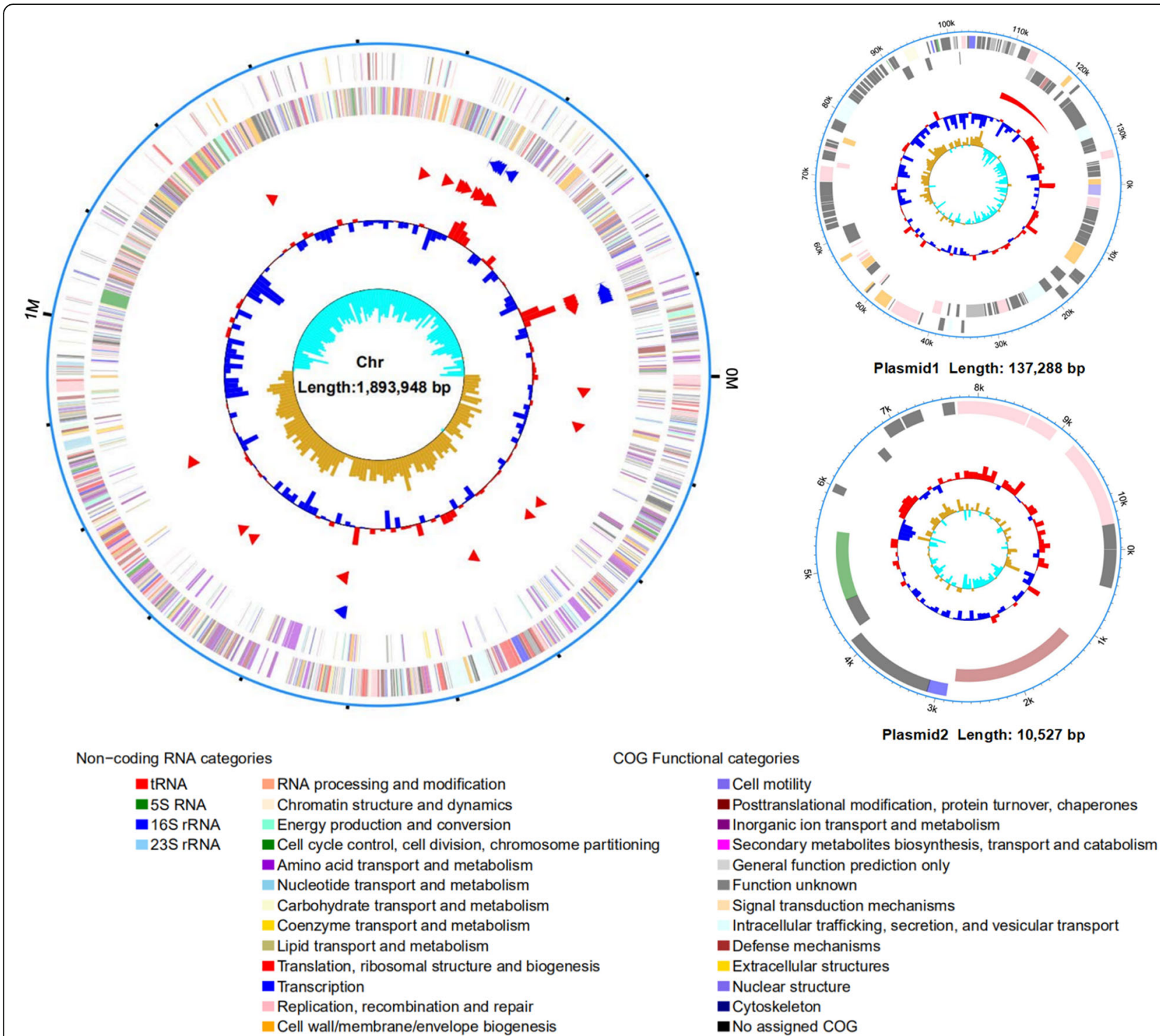

Fig. 2 Circular genome maps of L. taiwanensis CLG01 chromosome and the plasmids. From outside to the center: 1. forward CDSs colored by COG functional categories; 2. reverse CDSs colored by COG function categories; 3. rRNA; 4. tRNA; 6. GC content; and 7. GC skew. The circular plots were drawn with $\mathrm{R}$ package circlize

bacteriocin, LAP and lanthipeptide biosynthesis (Fig. 6). The BGC encoding bacteriocin was composed of 15 genes and exhibited a high sequence similarity of $77 \%$ with gassericin T, a broad-spectral bacteriocin produced by L. gasseri [32]. Detailed gene information of the three BGCs were shown in Table S3, S4, S5.

\section{Immunomodulatory effects of $L$. taiwanensis CLG01 in murine macrophage model}

To quantitatively assess the response of macrophages to L. taiwanensis CLG01, the production of cytokines TNF$\alpha$ and IL- 6 from macrophages was examined by enzymelinked immunosorbent assay (ELISA). The RAW 264.7 cells released high amounts of both cytokines upon the treatment of LPS. Compared to the control, both heatkilled bacteria and bacterial supernatant of L. taiwanensis CLG01 markedly increased the production of TNF- $\alpha$ (Fig. 7a) and IL-6 (Fig. 7b) of RAW 264.7 macrophages after $12 \mathrm{~h}$ of incubation. For heat-killed bacteria treatment, TNF- $\alpha$ level appeared to be higher than those of LPS-treated group. However, no statistical significance was observed. IL-6 level was significantly lower than those of LPS-treated group $(P=0.0033)$. In addition, the effect of bacterial supernatant on production of both cytokines was much weaker than heat-killed bacteria.

In order to evaluate the anti-inflammatory function of CLG01, production of anti-inflammatory cytokine IL-10 was measured in standard and LPS-treated conditions 


\section{COG Function Classification}

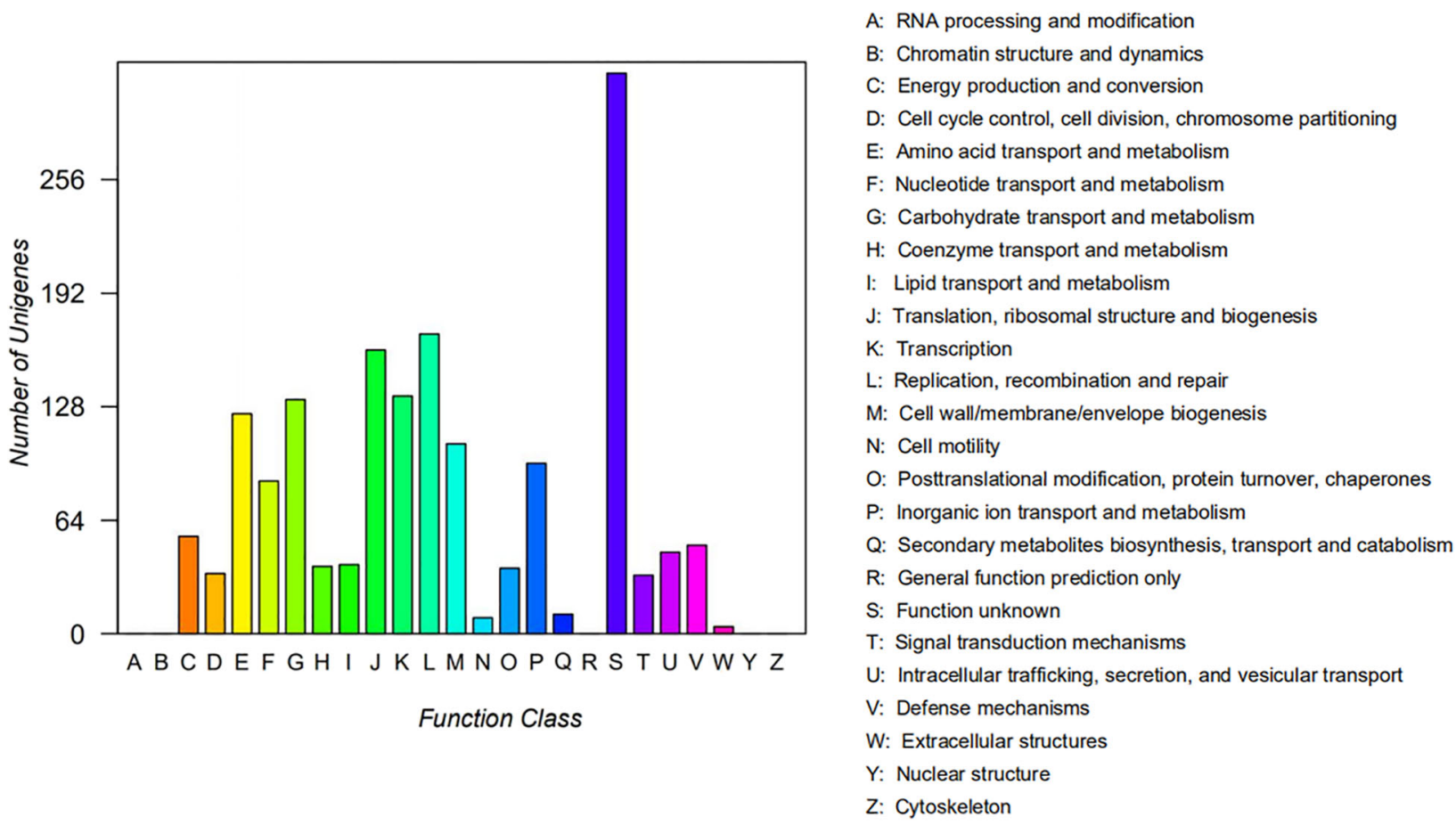

Fig. 3 Distribution of genes across COG functional categories in the genome of L. taiwanensis CLG01

a

\section{Acid Tolerance}

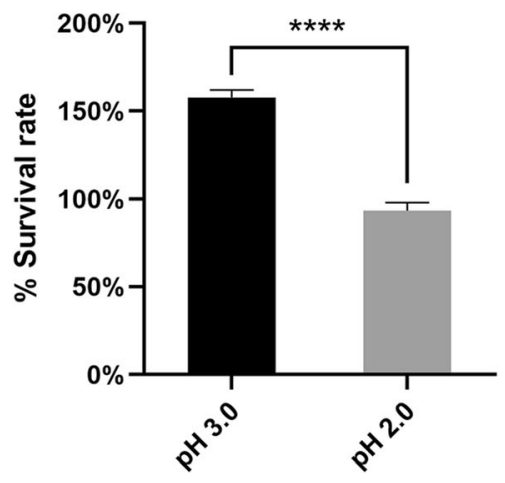

b

Bile salt tolerance

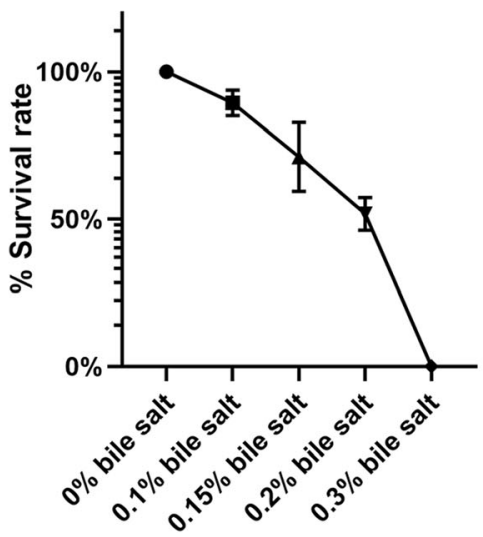

C

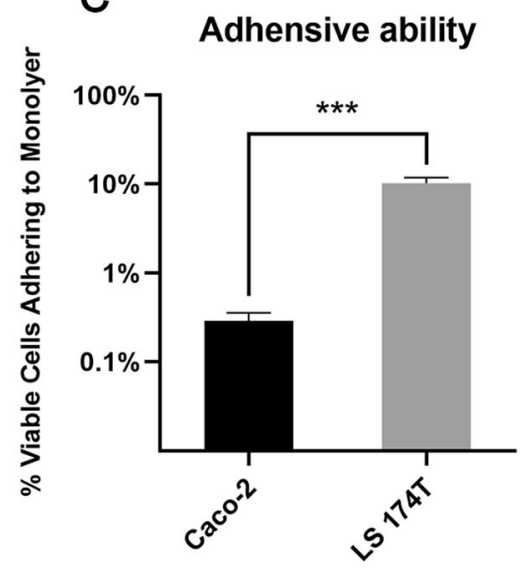

Fig. 4 Stress resistance and adhesive ability of L. taiwanensis CLG01. a Survival rate of CLG01 in the condition of pH 3.0 and pH 2.0.b Survival rate of CLG01 in the medium containing different concentrations of ox gall sodium cholate. c The percentage of viable cells adhering to Caco-2 and LS $174 \mathrm{~T}$ monolayers. Data expressed as mean \pm SD from three repeated experiments. Relevant statistically significant differences are as follow: $* * * P<0.001$ and $* * * * P<0.0001$ 
Table 2 Stress-related proteins of L. taiwanensis CLG01

\begin{tabular}{lll}
\hline Stress factors & Stress-related proteins & Locus tag \\
\hline Temperature & Molecular chaperone DnaJ & H1A07_03770 \\
Molecular chaperone DnaK & H1A07_03765 \\
& Molecular chaperone HtpX & H1A07_00400 \\
Molecular chaperone HsIO & H1A07_01505 \\
& Chaperonin GroEL & H1A07_02245 \\
& Co-chaperone GroES & H1A07_02240 \\
pH & H1A07_00580 \\
& FoF1-ATP synthase & H1A07_05945, \\
& & H1A07_05950, \\
& & H1A07_05955, \\
& & H1A07_05960, \\
& & H1A07_05970, \\
& & H1A07_05975, \\
Bile salt & & H1A07_05980 \\
Oxidative stress & H1A07_00295 \\
& Linear amide C-N hydrolase & H1A07_09050 \\
& Thiol peroxidase & H1A07_04795 \\
& Thioredoxin & H1A07_02340 \\
Pyruvate oxidase & H1A07_09225 \\
\hline
\end{tabular}

(Fig. 7c). Co-treatment with LPS was used to simulate the inflammatory condition. The results showed that both heat-killed bacteria $(P<0.0001)$ and bacterial supernatant $(P<0.0001)$ of $L$. taiwanensis CLG01 markedly increased the IL-10 production in the absence of LPS. IL-10 level of both groups was shown to be greater than LPS-only treated group. Importantly, statistically significant increase in the IL-10 production was observed when $1 \mu \mathrm{g} / \mathrm{mL}$ LPS co-treatment was administered $(P<0.001)$.

Further genomic analysis showed that L. taiwanensis CLG01 encoded proteins that involved in exopolysaccharide (EPS), peptidoglycan (PG), and polysaccharide biosynthesis, including exopolysaccharide biosynthesis protein (H1A07_05520, H1A07_05530) and peptidoglycan endopeptidase (H1A07_09465). Additionally, CLG01 encode two putative LTA synthase family proteins
(H1A07_06055, H1A07_07705) that involved in the biosynthesis of lipoteichoic acid (LTA).

\section{Discussion}

Genomic analysis combined with experimental studies provide an approach to study the characteristics of probiotics comprehensively. L. taiwanensis has been postulated to be a probiotic by many researchers [25-27], whereas supportive evidence is scarce. In the present study, a new strain was isolated from Peyer's patches of healthy mouse small intestine and identified as L. taiwanensis CLG01 based on 16S rRNA sequencing. The strain CLG01 was characterized for probiotic features, including the acid and bile salt tolerance, adhesion ability, antibacterial activity and in vitro immunomodulatory effects. The L. taiwanensis CLG01 displayed a degree of resistance to acid and bile salt with in vitro antibacterial activity and could enhance the innate immune responses in RAW 264.7 macrophages cells. Complete genome sequencing and analysis of L. taiwanensis CLG01 provided molecular biology clues for these beneficial effects.

Lactobacillus species of intestinal origin are considered intrinsically resistant to acidic environment. However, the acid tolerant properties vary widely among species [33]. L. taiwanensis CLG01 showed robust survival in low $\mathrm{pH}$ environments. The survival rates of CLG01 in $\mathrm{pH} 2.0$ and $\mathrm{pH} 3.0$ are consistent with some well-studied probiotic strains, like L. johnsonii ATCC 33200 and $L$. johnsonii 456. The strain CLG01 survived better than the probiotic strain L. acidophilus ATCC 4356 in pH 2.0 [34]. The presence of stress-related proteins in the genome and the high ability to metabolize carbohydrate may facilitate its resistance. Given the protective effects of metabolizable sugars on Lactobacilli in acidic environment, L. taiwanensis CLG01 may survive better in the fermented food [35]. L. taiwanensis was detected as one of the most abundant Lactobacillus species in the butter [36].

Although CLG01 could remain viable at bile salt concentration between 0 and $0.2 \%$, it was sensitive to $0.3 \%$ ox gall sodium cholate. The strain CLG01 only showed

Table 3 Antibacterial activity of L. taiwanensis CLG01 against pathogenic bacteria

\begin{tabular}{llll}
\hline Indicator bacteria & \multicolumn{2}{l}{ Inhibition zone $(\mathbf{m m})$} & $\mathbf{2 0} \mathbf{h}$ Supernatant \\
\cline { 2 - 4 } & $\mathbf{1 2} \mathbf{h}$ Supernatant & $\mathbf{1 6}$ h Supernatant & $11.71 \pm 0.43$ \\
\hline Escherichia coli & $12.16 \pm 0.74$ & $12.60 \pm 0.68$ & $11.30 \pm 0.23$ \\
Salmonella typhi & $10.93 \pm 0.85$ & $12.09 \pm 0.21$ & $12.90 \pm 0.46$ \\
Pseudomonas aeruginosa & $13.52 \pm 0.47$ & $14.72 \pm 0.28$ & $13.30 \pm 1.01$ \\
Staphylococcus aureus & $15.21 \pm 0.57$ & $15.82 \pm 0.62$ & $13.20 \pm 0.74$ \\
Bacillus subtilis & $12.36 \pm 0.42$ & $13.53 \pm 0.81$ & $9.89 \pm 0.62$ \\
Listeria monocytogenes & $8.81 \pm 0.21$ & $11.08 \pm 0.16$ &
\end{tabular}

Inhibition zone diameters are expressed as mean \pm SD in mm obtained from three independent experiments 

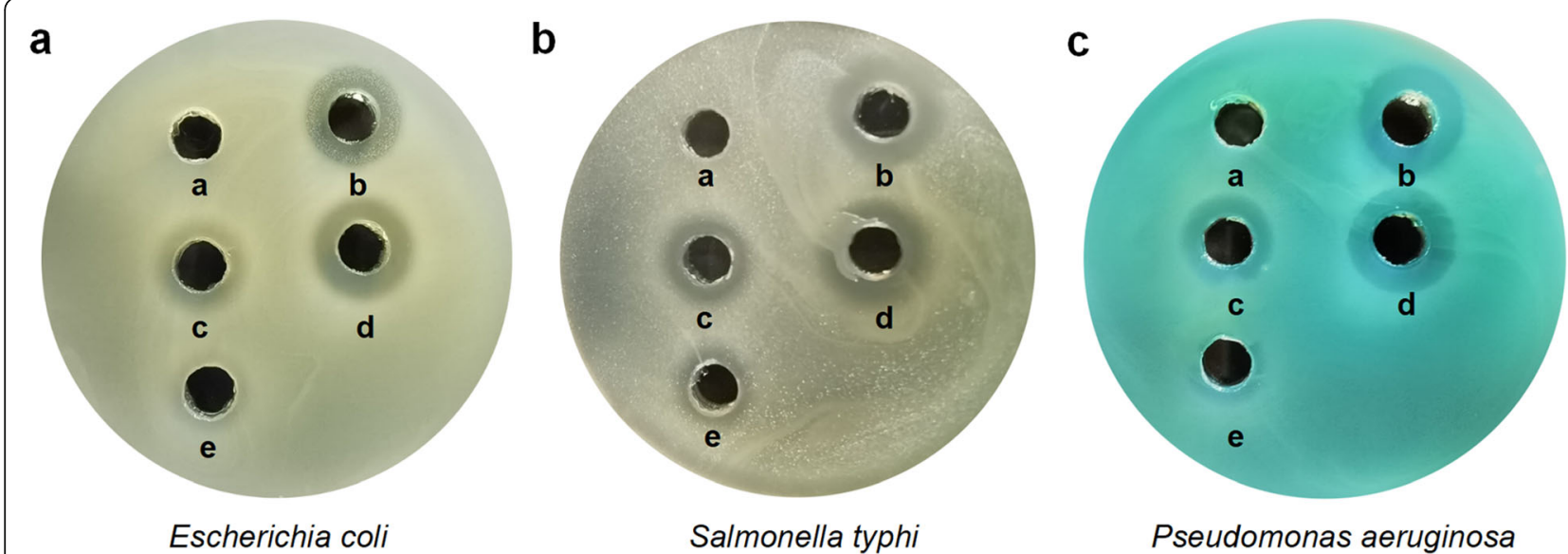

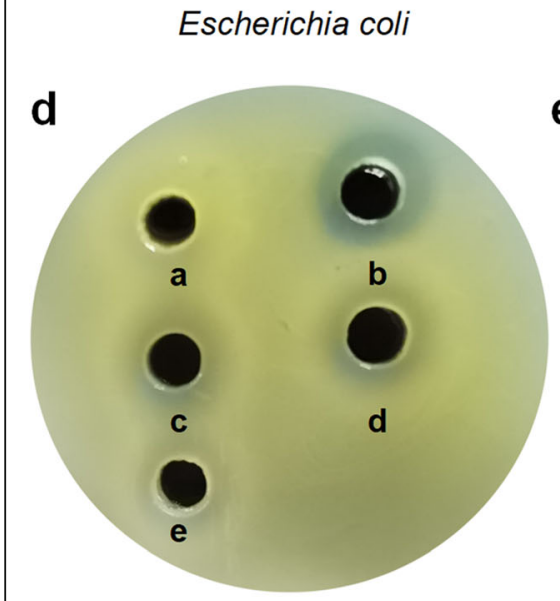

Staphylococcus aureus

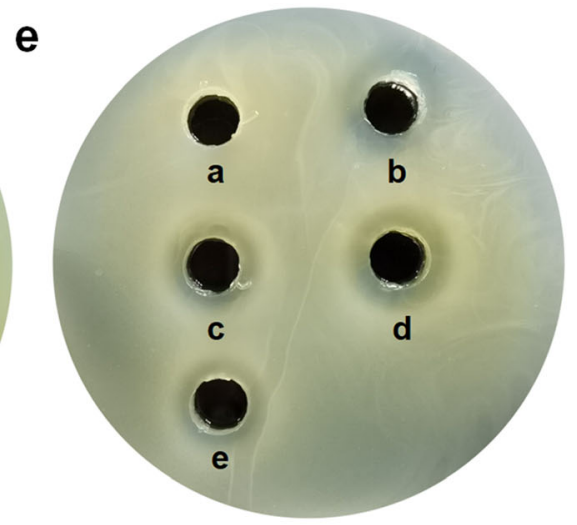

Bacillus subtilis
Pseudomonas aeruginosa

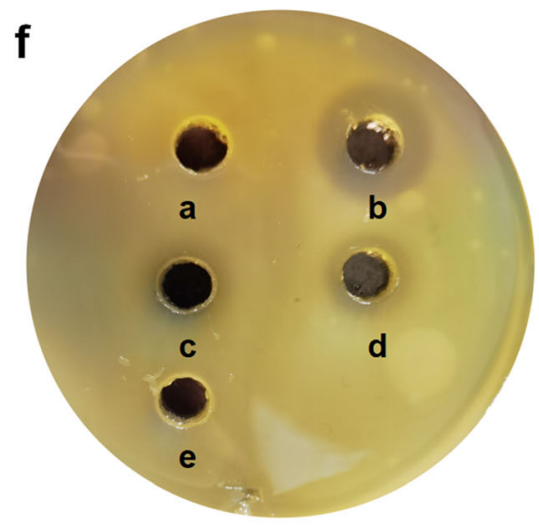

Listeria monocytogenes

Fig. 5 Inhibitory effect of L. taiwanensis CLG01 on the growth of pathogenic microorganisms. Inhibition zones were obtained from the following treatments: a, MRS broth; b, Ampicillin or gentamycin; c, Cell-free supernatant of L. taiwanensis CLG01; $\mathbf{d}$, Cell-free supernatant of L. taiwanensis CLG01 pretreated with proteinase inhibitor EDTA; e, Cell-free supernatant of L. taiwanensis CLG01 pretreated with proteinase

moderate bile salt tolerance relative to other probiotic strain, like L. plantarum $299 \mathrm{~V}$ [34]. This is probably due to its specific niche environment. Morphologically, the Peyer's patches in mouse small intestine showed a typical dome-shaped structure, which was defined as the subepithelial dome [37]. Compared to the small intestinal lumen, the concentration of bile salt is much lower at this site, from which the strain CLG01 was derived.

Similar to other reported probiotic Lactobacillus species, the adhesive ability of L. taiwanensis CLG01 to Caco-2 was lower than that to LS $174 \mathrm{~T}$ [34], which may be due to their distinct mucin profiles. Caco-2 cells express transmembrane mucins such as MUC1 and MUC3, whereas LS $174 \mathrm{~T}$ cells express a great amount of MUC2, which is the major secreted mucin that comprise intestinal mucus layer and provide a common binding site for commensal bacteria [38]. Furthermore, the in vivo intestinal environment is more complex than in vitro with syntrophic interactions between members of microbial communities. Lin et al. have reported the commensalism between $L$. reuteri and $L$. taiwanensis, in which $L$. reuteri enhances the colonization ability of $L$. taiwanensis in mouse gastrointestinal tract through coaggregation [39].

Probiotics control pathogenic infections through producing antimicrobial peptides, generating organic acid to lower local $\mathrm{pH}$, or enhancing functions of innate immune system [40-42]. In line with the finding reported by Kim et al. [27], the cell-free supernatant of L. taiwanensis CLG01 was also observed to limit the growth of both Gram-positive and Gram-negative pathogens to different degrees and the antimicrobial effect could be inhibited by the treatment of proteinase, indicating that the inhibitory effects might arise from proteinaceous substances. The in silico screen resulted in the identification of gene clusters encoding bacteriocin, LAP and lanthipeptide, which could at least partially explain its antimicrobial activity. Antibiotic resistance has become a global crisis in recent years and pose a threat to public health. New antibiotics alternatives are in urgent need. Bacteriocins produced by food-grade LAB are of great interests due to its heat stability and the inhibitory 


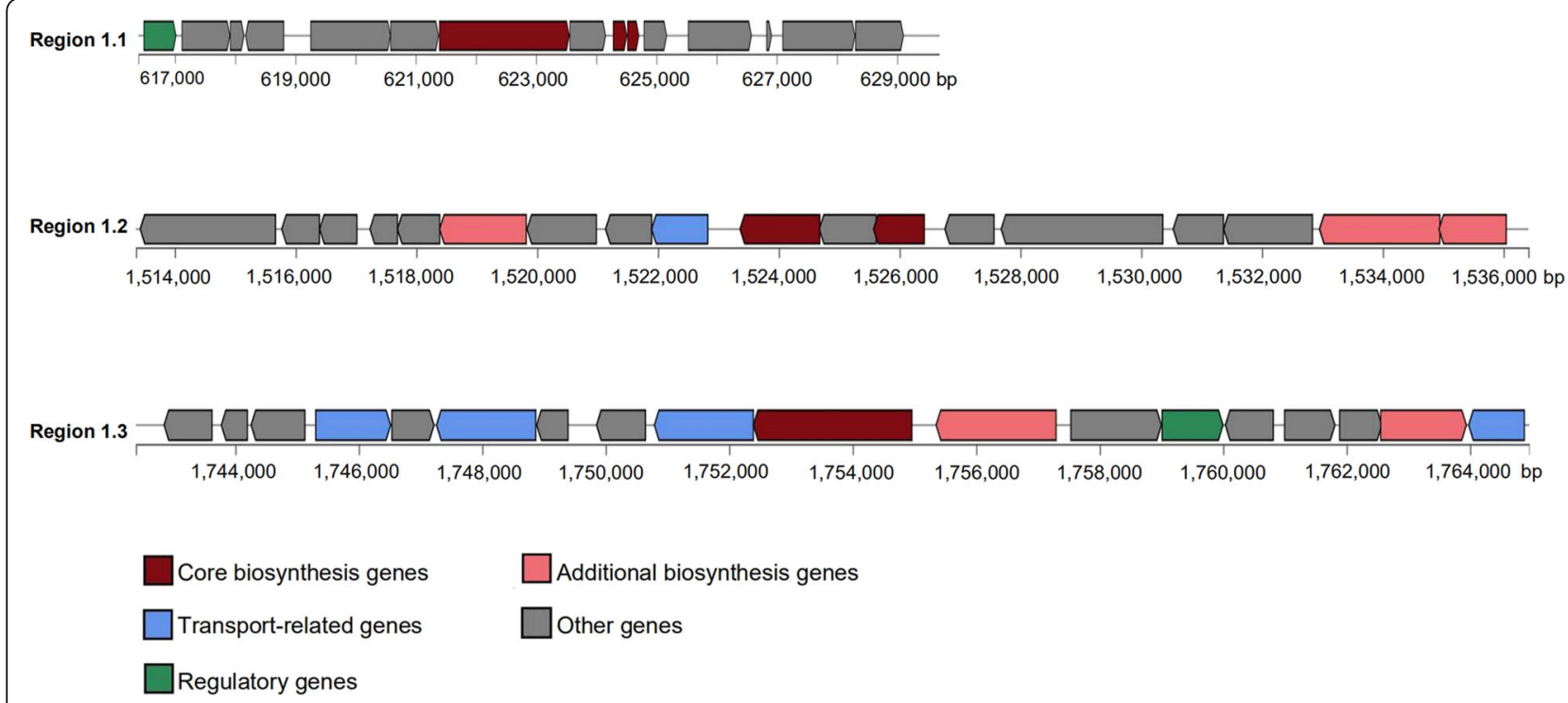

Fig. 6 Predicted biosynthetic gene clusters encoding secondary metabolites in the L. taiwanensis genome. The gene clusters encoding bacteriocin (Region 1.1), LAP (Region 1.2), and lanthipeptide (Region 1.3) are represented by arrows with different colors corresponding to the operons of different functions.

effects against pathogenic bacteria, which may facilitate their application in food preservation and treatment of infection [43]. The acidocin B derived from L. acidophilus and the helveticin J from L. helveticus are remarkable examples of bacteriocins produced by Lactobacillus strains [44]. The pediocin produced by Pediococcus strains has been approved by the FDA [45]. Lanthipeptides are a class of ribosomally synthesized and posttranslationally modified peptides (RiPPs) with characteristic lanthionine structures and show promising antimicrobial action against various Gram-positive pathogens and selective Gram-negative pathogens [46]. Certain

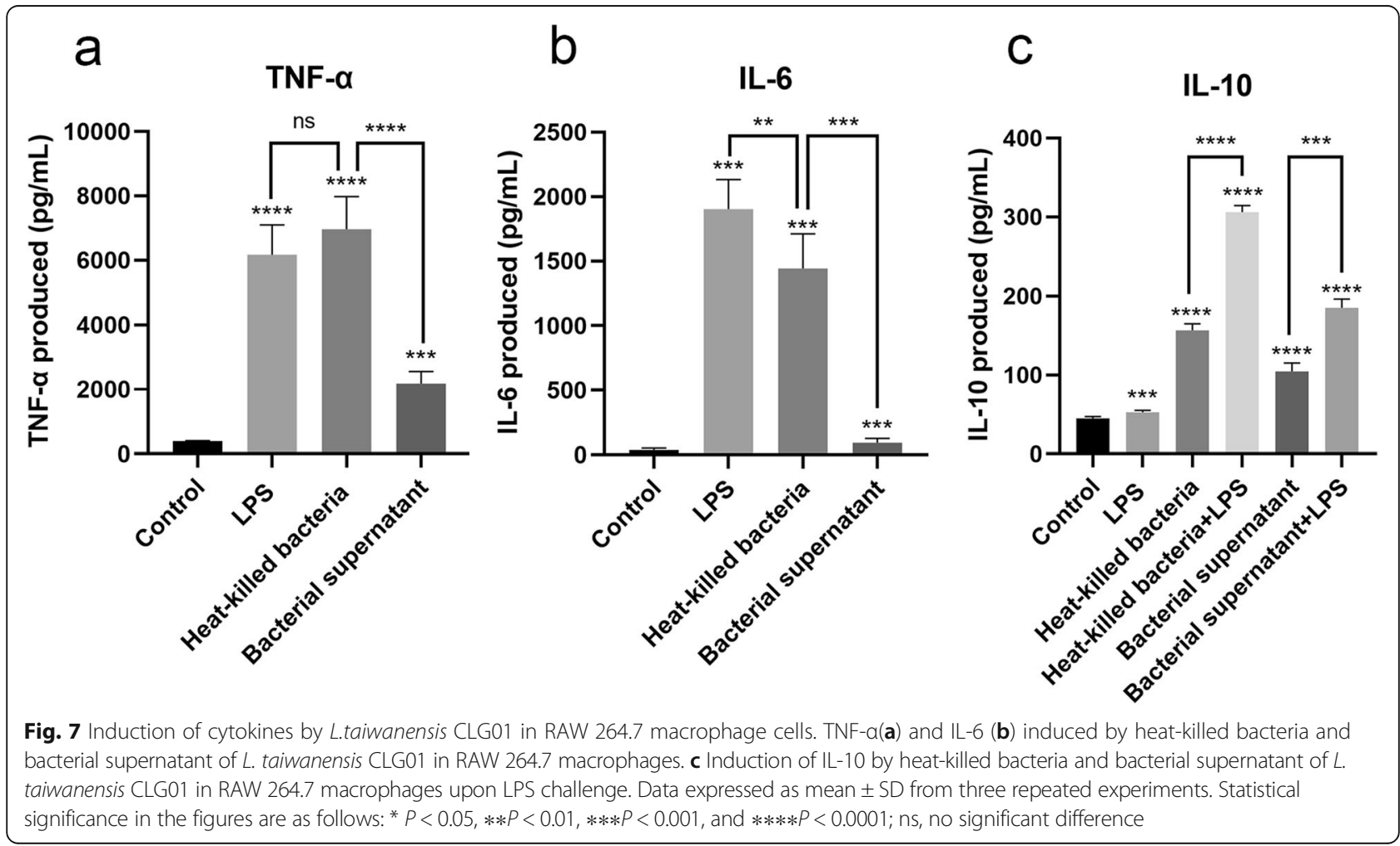


lantibiotics (e.g., nisin and haloduracin) have been used together with traditional antibiotics to fight against multidrug-resistant bacteria [47]. Functional genome mining can offer an effective approach to identify new members of this family and their biosynthetic machinery. In this sense, L. taiwanensis may serve as a new source of bioactive antibacterial compounds. Further work will be done to confirm the expression of these genomepredicted metabolites and establish their biosynthesis pathway as well as detailed mode of action.

We intended to screen the Lactobacillus strains with immunomodulating capacity in this study. Peyer's patches, the gut-associated lymphoid follicles, are inductive sites for mucosal immune responses [48] and may serve as reservoir for unique microorganisms with immunomodulatory property. It has been reported that specific L. reuteri colonized within mouse Peyer's patches could increase the cytokines production of RAW 264.7 cells [49] and modulate the secretion of secretory immunoglobulin A [50].

Macrophages are major participants in innate immunity and the most rapid cell type to respond to pathogens' invasion [51]. TNF- $\alpha$ and IL- 6 are important cytokines involved in activation of macrophages and recruitment of immune cells $[52,53]$. In this work, heat-killed bacteria and the supernatant containing soluble metabolites of L. taiwanensis CLG01 were capable of activating RAW 264.7 macrophage cells. The effect of heat-killed bacteria was more marked, indicating that the immune responses mostly result from surface cell components of CLG01. It has been established that extracellular proteins of Lactobacillus species can elicit immune responses through activating distinct pattern recognition receptors present in epithelial cells and immune cells. LTA is the major microbe-associated molecular pattern of Gram-positive bacteria and the agonist of Toll-like receptor 2 [54], while PGs are more likely to activate NODlike receptors [55]. The presence of genes related to LTA and PG biosynthesis provide a clue to the mechanism of macrophages activation. In particular, L. taiwanensis CLG01 could induce the secretion of IL-10 in vitro, a potent anti-inflammatory cytokine essential for restraining excessive inflammatory and immune responses [56]. The combined treatments of strain CLG01 with LPS resulted in a greater IL-10 secretion, suggesting that $L$. taiwanensis CLG01 might exert a greater anti-inflammatory effect in the context of inflammation. Previous studies have reported the anti-inflammatory activity of EPS and the role it played in macrophages activation [57, 58]. Although in vitro models cannot fully represent the real situation, the results obtained from co-culture assays can be predictive of the in vivo immunomodulatory properties of lactobacilli. For further therapeutic application, animal models with diverse immunological status should be established to determine the effectiveness of the Peyer's patchesderived L. taiwanensis CLG01.

\section{Conclusion}

In the current study, we systematically characterized the probiotic properties of L. taiwanensis for the first time and disclosed its complete genome sequence. The strain CLG01 of L. taiwanensis, isolated from Peyer's patches, showed the ability to survive in acid and bile salt. Moreover, CLG01 exhibited inhibitory effects against multiple pathogens and induced the immune responses of macrophages in vitro. This study will provide a considerable insight into the physiological functions of L. taiwanensis and the corresponding molecular mechanisms and consequently contribute to its application in producing novel antibiotics and regulating intestinal immunity.

\section{Methods}

\section{Isolation and culture of the bacteria strain}

Peyer's patches samples were collected from small intestine of healthy C57BL/6 mice. The study was approved by the Ethical Committee on Scientific Research of Shandong University Qilu Hospital (DWLL-2020-003). All animal experiments have followed ARRIVE guidelines. We confirm that all methods were carried out in accordance with relevant guidelines and regulations. The Peyer's patches samples were fully homogenized and ten-fold serial dilutions of the homogenates were spread onto MRS agar plates (Qingdao Haibo Biotechnology Company, Qingdao, China) and incubated at $37^{\circ} \mathrm{C}$ for $48 \mathrm{~h}$ under microaerophilic condition. Single colonies were selected based on their colony morphologies and purified by re-streaking on MRS agar plates. The isolates were Gram-stained. SEM (Zeiss, Oberkochen, Germany) was used to observe the bacterial morphology. Bacterial genomic DNA was extracted and the V3, V4 region of 16S rRNA gene was amplified through PCR using primers 27F (5'-AGAGTTTGATCMTGGCTCAG-3') and 1492R ( $5^{\prime}$-TACGGYTACCTTGTTACGACTT-3') as described before [59]. The amplification products were visualized using $1 \%$ agarose gel electrophoresis and submitted for sequencing. The sequences obtained were compared to those in National Center Biotechnology Information (NCBI) database using nucleotide BLAST tool. Isolates were stored in MRS broth containing $20 \%$ (v/v) glycerol at $-80^{\circ} \mathrm{C}$.

\section{Complete genome sequencing and assembly and annotation}

Bacterial cell pellet was harvested by centrifugation and total DNA was extracted using E.Z.N.A ${ }^{\circ}$ Bacteria DNA kit (Omega Bio-tek, Norcross, USA). Complete genome was sequenced with a combination of Illumina platform (Illumina, TX, USA) and Oxford Nanopore platform 
(Oxford Nanopore Technologies, Oxford, UK). The reads were assembled using ABySS 2.0 [60]. GeneMarkS [61] was adopted for the prediction of protein-coding RNA in the whole genome. The prediction of rRNA and tRNA were proceeded by RNAmmer 1.2 [62] and tRNAscan-SE 2.0.4 [63]. Functional gene annotation was based on NCBI non-redundant database [64], COG database [65], and CAZymes database [66]. Genome sequences of $L$. taiwanensis CLG01 have been submitted to GenBank under accession number CP059276 (chromosome), CP059277 (plasmid1), and CP059278 (plasmid2).

\section{Phylogenetic tree and bioinformatic analysis}

Ten strains of Lactobacillus species, one strain of Enterococcus faecalis and one strain of Escherichia coli with complete genomes were downloaded from NCBI database. Single copy, orthologous genes shared by all species were selected and multiple-sequence alignments of these genes were performed using MAFFT [67]. Aligned sequences were concatenated to obtain whole-genomewide alignment for phylogenetic analyses. A neighborjoining tree was generated and rooted by FastTree [68]. Bootstrap values were obtained by running 1000 bootstrap replicates. Secondary metabolites gene clusters were predicted using antiSMASH 5 [69]. The PathogenFinder (https://cge.cbs.dtu.dk//services/ResFinder/) was used to estimate the pathogenicity of CLG01.

\section{Acid and bile salt tolerance assays}

Acid tolerance assay was performed as described before [70] with little modification.

MRS broth was adjusted to $\mathrm{pH} 2.0$ and 3.0 with $1 \mathrm{M}$ hydrochloric acid. L. taiwanensis CLG01 was cultured overnight in MRS broth at $37^{\circ} \mathrm{C}$ and bacterial suspension $\left(1 \times 10^{8}\right.$ cells $\left./ \mathrm{mL}\right)$ was inoculated into acidified MRS broth and cultured for $2 \mathrm{~h}$. After incubation, bacterial suspension was serial diluted, plated on MRS agar and incubated at $37^{\circ} \mathrm{C}$ for $48 \mathrm{~h}$. Survival rates (\%) was calculated by comparing final count of viable cells with the initial count. To test the bile salt tolerance of $L$. taiwanensis CLG01, bacterial suspension was serially diluted and plated onto MRS agar plates containing 0$0.3 \%(\mathrm{w} / \mathrm{v})$ ox gall sodium cholate (Sangon Biotech, Shanghai, China). Inoculated agar plates were incubated at $37^{\circ} \mathrm{C}$ for $48 \mathrm{~h}$ and the viable cells were counted. Bile salt tolerance was determined by calculating the ratio (\%) of viable cells compared control without bile salt [71].

\section{Adhesion assay}

The adhesion assay was performed as described before [34]. Human colorectal adenocarcinoma cell line Caco-2 and human goblet cell line LS $174 \mathrm{~T}$ were purchased from American Type Culture Collection (ATCC) and grown in Dulbeccos modified Eagles medium (DMEM) containing $10 \%$ fetal bovine serum (FBS) and $1 \%$ penicillin-streptomycin at $37^{\circ} \mathrm{C}$ in a $5 \% \mathrm{CO}_{2}$ atmosphere. Caco- 2 cells and LS $174 \mathrm{~T}$ cells were seeded respectively in 12 -well plates at $5 \times 10^{5}$ cells/well and grown to confluent monolayers. Overnight cultures of $L$. taiwanensis CLG01 were centrifugated, rinsed, and suspended in antibiotic-free DMEM to a concentration of $2-5 \times 10^{8}$ cells $/ \mathrm{mL}$. Cell monolayers were washed twice with sterile phosphate buffered saline (PBS). A $1 \mathrm{~mL}$ of suspended bacterial sample was added to each well. After $2 \mathrm{~h}$ of incubation, supernatants were removed and the monolayers were washed with PBS for 3 times to remove the non-adherent bacteria. Then cell monolayers were agitated vigorously with micropipette tips and suspended in $1 \mathrm{~mL}$ PBS. The resulting suspensions were serially diluted and plated on MRS agar plates. The agar plates were incubated at $37^{\circ} \mathrm{C}$ for $48 \mathrm{~h}$ and the percentage of viable cells were calculated.

\section{Antibacterial activity test}

The antibacterial activity of L. taiwanensis CLG01 was determined by well agar diffusion method described by Zheng et al. [72] with little modification. Standard strains of pathogenic bacteria were purchased from China Medical Microorganism Culture Collection (CMCC), including Escherichia coli CMCC 44102, Staphylococcus aureus CMCC 26003, Pseudomonas aeruginosa CMCC 10104, Bacillus subtilis ATCC 6633, Salmonella typhi CMCC 50071, and Listeria monocytogenes ATCC 19115. These strains were used as the indicator bacteria and cultured in Luria-Bertani (LB) broth overnight at $37^{\circ} \mathrm{C}$ with shaking at $200 \mathrm{rpm}$. L. taiwanensis CLG01 were cultured in MRS broth at $37^{\circ} \mathrm{C}$, with aliquots taken at 12,16 , and $20 \mathrm{~h}$ of incubation. The cell-free supernatant of CLG01 was obtained by centrifugating at $8000 \mathrm{~g}$ for $15 \mathrm{~min}$ and filtering via $0.22-\mu \mathrm{m}$ filters. LB agar was autoclaved and cooled to a temperature of $45^{\circ} \mathrm{C}$. Then $10 \%(\mathrm{v} / \mathrm{v})$ indicator bacteria liquid was added. Approximately $25 \mathrm{~mL} \mathrm{LB}$ agar was poured over a $9.0 \mathrm{~cm}$ petri dish and allowed to solidify at room temperature. Wells were punched on the plates with $200 \mu \mathrm{L}$ cell-free supernatant added into each well. An equal volume of fresh MRS broth was used as a negative control. Ampicillin $(20 \mu \mathrm{g} / \mathrm{mL})$ served as the positive control for Escherichia coli, Staphylococcus aureus, Salmonella typhi and Listeria monocytogenes, while gentamycin $(20 \mu \mathrm{g} / \mathrm{mL})$ served as the positive control for Pseudomonas aeruginosa and Bacillus subtilis. After incubation at $37^{\circ} \mathrm{C}$ for $24 \mathrm{~h}$, diameters of inhibition zones were measured. Additionally, $1 \mathrm{mg} / \mathrm{mL}$ pepsin enzyme and $5 \mathrm{mM}$ EDTA were used to pretreat the cell-free supernatant for $2 \mathrm{~h}$ respectively. 
The mixtures were assayed for antibacterial activity as described above.

\section{Cytokine induction in mouse RAW 264.7 macrophages cells}

Bacterial cell pellet of L. taiwanensis CLG01 was harvested and washed, and the concentration was adjusted to $1 \times 10^{8}$ cells $/ \mathrm{mL}$ with sterile saline. Heatkilled bacteria was prepared by incubation in a metal bath at $100^{\circ} \mathrm{C}$ for $15 \mathrm{~min}$ and resuspended in DMEM. For the preparation of bacterial supernatant, the bacteria were resuspended in DMEM and incubated at $37^{\circ} \mathrm{C}$ for $2 \mathrm{~h}$. Subsequently, bacteria were removed by centrifugation and filtration via a $0.22-\mu \mathrm{m}$ filter. The supernatants were retained for next step experiment. Mouse macrophage cell line RAW 264.7 was purchased from ATCC and the culture condition was the same as Caco- 2 cells and LS $174 \mathrm{~T}$ cells. Approximately $1 \times 10^{6}$ cells were seeded in each well of 12 well cell culture plates and stabilized overnight. Heatkilled bacteria and bacterial supernatant were administered. Cells treated with $1 \mu \mathrm{g} / \mathrm{mL}$ LPS (Sigma-Aldrich, MO, USA) were used as positive control. Nontreated cells were used as negative control. After $12 \mathrm{~h}$ of treatment, supernatant of each group was collected and analyzed for TNF- $\alpha$ and IL- 6 levels using ELISA (Lianke Biotech, Hangzhou, China) according to the manufacturers' instructions.

\section{Anti-inflammatory effects of $L$. taiwanensis CLG01 upon LPS challenge}

To determine the anti-inflammatory effects of CLG01, cells and bacteria preparations were the same as described above. Macrophage cells were treated with heatkilled bacteria and bacterial supernatant for $12 \mathrm{~h}$ in the presence or absence of $1 \mu \mathrm{g} / \mathrm{mL}$ LPS. Similarly, cells treated with $1 \mu \mathrm{g} / \mathrm{mL}$ LPS were used as positive control with the non-treated cells as negative control. IL-10 levels of the resulting supernatants were determined by ELISA.

\section{Statistical analysis}

All experiments were repeated three times. Statistical analysis was performed by Graphpad Prism 8. Data was presented as the mean \pm standard deviation (SD). Two-tailed, unpaired Student's $t$ tests were used to assess the significance of differences in acid tolerance and adhesion assays. Results of cytokines production were analyzed using non-parametric tests (MannWhitney test, Kruskal-Wallis test).

\section{Supplementary Information}

The online version contains supplementary material available at https://doi. org/10.1186/s12866-021-02127-z.
Additional file 1: Table S1. COG function classification of encoding proteins in the genome of $L$. taiwanensis CLG01. Table S2. The phosphotransferase system (PTS) in the genome of L. taiwanensis CLG01. Table S3. Detailed information of the bacteriocin biosynthetic gene cluster in L. taiwanensis CLG01 genome. Table S4. Detailed information of the LAP biosynthetic gene cluster in L. taiwanensis CLG01 genome. Table S5. Detailed information of the Lanthipeptide biosynthetic gene cluster in L. taiwanensis CLG01 genome. Figure S1. Colony morphology of $L$. taiwanensis CLG01 on MRS agar plate after $48 \mathrm{~h}$ of incubation. Figure S2. Morphology of L. taiwanensis CLG01 under a scanning electron microscope (SEM).

\section{Abbreviations}

LPS: Lipopolysaccharide; BGCs: Biosynthetic gene clusters; LAP: Linear azol(in)e-containing peptide; LAB: Lactic acid bacteria; MRS: De Man Rogosa Sharpe; SEM: Scanning electron microscopy; COG: Clusters of orthologous groups; PTS: Phosphotransferase system; CAZymes: Carbohydrate-active enzymes; ELISA: Enzyme-linked immunosorbent assay;

EPS: Exopolysaccharide; PG: Peptidoglycan; LTA: Lipoteichoic acid; RiPPs: Ribosomally synthesized and posttranslationally modified peptides; NCBI: National Center Biotechnology Information; ATCC: American Type Culture Collection; DMEM: Dulbeccos modified Eagles medium; CMCC: China Medical Microorganism Culture Collection; FBS: Fetal bovine serum; PBS: Phosphate buffered saline; LB: Luria-Bertani; SD: Standard deviation

\section{Acknowledgements}

We deeply appreciate Dong Zhao, Lei-qi Xu, Tong Liu, Jun-yan Qu, Yinhe Sikong, Hong-yu Zhao, Teng-fei Wang, Lin Lin, Kai-ruo Wang for their valuable supports and advice during the research and manuscript drafting. We thank the colleagues of Shanghai Majorbio for assistance in genome sequencing.

\section{Authors' contributions}

YQL, XLZ and XYL conceived the study. XYL and LXL designed the study and were major contributors in writing and revising the manuscript. XYL analyzed the sequencing data. $X Y L, Y L, R C Z$, and BL performed the experiments; XG, SCF and BYJ provided technical assistance. All authors have read and approved the manuscript.

\section{Funding}

This study was supported by the National Natural Science Foundation of China (81873550 and 81670489), Key Research and Development Program of Shandong Province (2019GHZ022 and 2018CXGC1209).

\section{Availability of data and materials}

The dataset of complete genome sequencing of L. taiwanensis CLG01 have been deposited to National Center Biotechnology Information repository with accession number CP059276-CP059278.

\section{Ethics approval and consent to participate}

The study was approved by the Ethical Committee on Scientific Research of Shandong University Qilu Hospital (DWLL-2020-003). The animal studies were performed according to the ARRIVE guidelines. All methods were carried out in accordance with relevant guidelines and regulations.

\section{Consent for publication}

Not applicable.

\section{Competing interests}

The authors declared that they have no competing interests.

\section{Author details}

'Department of Gastroenterology, Qilu Hospital, Cheeloo College of Medicine, Shandong University, 107 Wenhuaxi Road, Jinan 250012, Shandong Province, China. ${ }^{2}$ Laboratory of Translational Gastroenterology, Qilu Hospital, Cheeloo College of Medicine, Shandong University, Jinan, Shandong, China. ${ }^{3}$ Robot engineering laboratory for precise diagnosis and therapy of Gl tumor, Qilu Hospital, Cheeloo College of Medicine, Shandong University, Jinan, Shandong, China. 
Received: 10 November 2020 Accepted: 11 February 2021

\section{Published online: 27 February 2021}

\section{References}

1. Wang G, Huang S, Wang Y, Cai S, Yu H, Liu H, et al. Bridging intestinal immunity and gut microbiota by metabolites. Cell Mol Life Sci. 2019;76(20): 3917-37.

2. Lin L, Zhang J. Role of intestinal microbiota and metabolites on gut homeostasis and human diseases. BMC Immunol. 2017;18(1):2.

3. Halfvarson J, Brislawn CJ, Lamendella R, Vázquez-Baeza Y, Walters WA, Bramer LM, et al. Dynamics of the human gut microbiome in inflammatory bowel disease. Nat Microbiol. 2017;2:17004.

4. Cremonesi E, Governa V, Garzon JFG, Mele V, Amicarella F, Muraro MG, et al. Gut microbiota modulate T cell trafficking into human colorectal cancer. Gut. 2018;67(11):1984-94.

5. Flemer B, Lynch DB, Brown JMR, Jeffery IB, Ryan FJ, Claesson MJ, et al. Tumour-associated and non-tumour-associated microbiota in colorectal cancer. Gut. 2017;66(4):633-43.

6. Janney A, Powrie F, Mann EH. Host-microbiota maladaptation in colorectal cancer. Nature. 2020;585(7826):509-17.

7. Giau W, Wu SY, Jamerlan A, An SSA, Kim SY, Hulme J. Gut microbiota and their neuroinflammatory implications in Alzheimer's disease. Nutrients. 2018; 10(11):1765

8. Sampson TR, Debelius JW, Thron T, Janssen S, Shastri GG, Ithan ZE, et al. Gut microbiota regulate motor deficits and neuroinflammation in a model of Parkinson's disease. Cell. 2016;167(6):1469-80.

9. Hartstra AV, Bouter KEC, Bäckhed F, Nieuwdorp M. Insights into the role of the microbiome in obesity and type 2 diabetes. Diabetes Care. 2015;38(1): 159-65.

10. Lee P, Yacyshyn BR, Yacyshyn MB. Gut microbiota and obesity: an opportunity to alter obesity through faecal microbiota transplant (FMT). Diabetes Obes Metab. 2019;21(3):479-90.

11. Liu X, Cao S, Zhang X. Modulation of gut microbiota-brain axis by probiotics, prebiotics, and diet. J Agric Food Chem. 2015;63(36):7885-95.

12. Binda S, Hill C, Johansen E, Obis D, Pot B, Sanders ME, et al. Criteria to qualify microorganisms as "probiotic" in foods and dietary supplements. Front Microbiol. 2020;11:1662

13. Doyle N, Mbandlwa P, Kelly WJ, Attwood G, Li Y, Ross RP, et al. Use of lactic acid bacteria to reduce methane production in ruminants, a critical review. Front Microbiol. 2019;10:2207.

14. Zhang Z, LV J, Pan L, Zhang Y. Roles and applications of probiotic Lactobacillus strains. Appl Microbiol Biotechnol. 2018;102(19):8135-43.

15. Paveljšek $D$, Juvan $P$, Košir $R$, Rozman $D$, Hacin $B$, Ivičak-Kocjan $K$, et al. Lactobacillus fermentum L930BB and Bifidobacterium animalis subsp. animalis IM386 initiate signalling pathways involved in intestinal epithelial barrier protection. Benef Microbes. 2018;9(3):515-25.

16. Rocha-Ramírez LM, Pérez-Solano RA, Castañón-Alonso SL, Moreno Guerrero SS, Ramírez Pacheco A, García Garibay M, et al. Probiotic strains stimulate the inflammatory response and activate human macrophages. J Immunol Res. 2017;2017:4607491.

17. Eslami M, Yousefi B, Kokhaei P, Hemati M, Nejad ZR, Arabkari V, et al. Importance of probiotics in the prevention and treatment of colorectal cancer. J Cell Physiol. 2019;234(10):17127-43.

18. Han X, Lee A, Huang S, Gao J, Spence JR, Owyang C. Lactobacillus rhamnosus GG prevents epithelial barrier dysfunction induced by interferon-gamma and fecal supernatants from irritable bowel syndrome patients in human intestinal enteroids and colonoids. Gut Microbes. 2019; 10(1):59-76.

19. McFarland LV, Ship N, Auclair J, Millette M. Primary prevention of Clostridium difficile infections with a specific probiotic combining Lactobacillus acidophilus, L. casei, and L. rhamnosus strains: assessing the evidence. J Hosp Infect. 2018;99(4):443-52.

20. Aureli P, Capurso L, Castellazzi AM, Clerici M, Giovannini M, Morelli L, et al. Probiotics and health: an evidence-based review. Pharmacol Res. 2011;63(5): 366-76.

21. Wang L-T, Kuo H-P, Wu Y-C, Tai C-J, Lee F-L. Lactobacillus taiwanensis sp. nov., isolated from silage. Int J Syst Evol Microbiol. 2009;59(Pt 8):2064-8.

22. Sarmiento-Rubiano L-A, Berger B, Moine D, Zúñiga M, Pérez-Martínez G, Yebra MJ. Characterization of a novel Lactobacillus species closely related to Lactobacillus johnsonii using a combination of molecular and comparative genomics methods. BMC Genomics. 2010;11:504.
23. Morikawa M, Tsujibe S, Kiyoshima-Shibata J, Watanabe Y, Kato-Nagaoka N, Shida K, et al. Microbiota of the small intestine is selectively engulfed by phagocytes of the lamina propria and Peyer's patches. PLoS One. 2016; 11(10):e0163607.

24. Reynolds LA, Smith KA, Filbey KJ, Harcus Y, Hewitson JP, Redpath SA, et al. Commensal-pathogen interactions in the intestinal tract: lactobacilli promote infection with, and are promoted by, helminth parasites. Gut Microbes. 2014;5(4):522-32

25. Kwasniewski W, Wolun-Cholewa M, Kotarski J, Warchol W, Kuzma D, Kwasniewska A, et al. Microbiota dysbiosis is associated with HPV-induced cervical carcinogenesis. Oncol Lett. 2018;16(6):7035-47.

26. Zhang $Y$, Wang $X-L$, Zhou M, Kang $C$, Lang H-D, Chen M-T, et al. Crosstalk between gut microbiota and Sirtuin-3 in colonic inflammation and tumorigenesis. Exp Mol Med. 2018;50(4):21.

27. Kim SW, Ha YJ, Bang KH, Lee S, Yeo J-H, Yang H-S, et al. Potential of bacteriocins from for producing bacterial ghosts as a next generation vaccine. Toxins (Basel). 2020;12(7):432.

28. D'Souza S, Garcia-Cabado A, Yu F, Teter K, Lukacs G, Skorecki K, et al. The epithelial sodium-hydrogen antiporter $\mathrm{Na}+/ \mathrm{H}+$ exchanger 3 accumulates and is functional in recycling endosomes. J Biol Chem. 1998;273(4):2035-43.

29. Zhang W, Guo H, Cao C, Li L, Kwok L-Y, Zhang H, et al. Adaptation of Zhang to gentamycin involves an alkaline shock protein. Front Microbiol. 2017;8:2316.

30. Chand D, Panigrahi P, Varshney N, Ramasamy S, Suresh CG. Structure and function of a highly active bile salt hydrolase $(\mathrm{BSH})$ from enterococcus faecalis and post-translational processing of BSH enzymes. Biochim Biophys Acta, Proteins Proteomics. 2018;1866(4):507-18.

31. de Melo Pereira GV, de Oliveira CB, Magalhães Júnior Al, Thomaz-Soccol V, Soccol CR. How to select a probiotic? A review and update of methods and criteria. Biotechnol Adv. 2018;36(8):2060-76.

32. Arakawa $K$, Kawai $Y$, lioka $H$, Tanioka M, Nishimura J, Kitazawa $H$, et al. Effects of gassericins $a$ and $T$, bacteriocins produced by Lactobacillus gasseri, with glycine on custard cream preservation. J Dairy Sci. 2009;92(6):2365-72

33. Kailasapathy K, Chin J. Survival and therapeutic potential of probiotic organisms with reference to Lactobacillus acidophilus and Bifidobacterium spp. Immunol Cell Biol. 2000;78(1):80-8.

34. Davoren MJ, Liu J, Castellanos J, Rodríguez-Malavé NI, Schiestl RH. A nove probiotic, Lactobacillus johnsonii 456, resists acid and can persist in the human gut beyond the initial ingestion period. Gut Microbes. 2019;10(4): 458-80.

35. Corcoran BM, Stanton C, Fitzgerald GF, Ross RP. Survival of probiotic lactobacilli in acidic environments is enhanced in the presence of metabolizable sugars. Appl Environ Microbiol. 2005;71(6):3060-7.

36. Syromyatnikov MY, Kokina AV, Solodskikh SA, Panevina AV, Popov ES, Popov VN. High-throughput 165 rRNA gene sequencing of butter microbiota reveals a variety of opportunistic pathogens. Foods. 2020;9(5):608.

37. Biram A, Strömberg A, Winter E, Stoler-Barak L, Salomon R, Addadi Y, et al. $B C R$ affinity differentially regulates colonization of the subepithelial dome and infiltration into germinal centers within Peyer's patches. Nat Immunol. 2019;20(4):482-92.

38. van Klinken BJ, Oussoren E, Weenink JJ, Strous GJ, Büller HA, Dekker J, et al. The human intestinal cell lines Caco-2 and LS174T as models to study celltype specific mucin expression. Glycoconj J. 1996;13(5):757-68.

39. Lin XB, Wang T, Stothard P, Corander J, Wang J, Baines JF, et al. The evolution of ecological facilitation within mixed-species biofilms in the mouse gastrointestinal tract. ISME J. 2018;12(11):2770-84.

40. Kamada N, Chen GY, Inohara N, Núñez G. Control of pathogens and pathobionts by the gut microbiota. Nat Immunol. 2013;14(7):685-90.

41. Kobayashi KS, Chamaillard M, Ogura Y, Henegariu O, Inohara N, Nuñez G, et al. Nod2-dependent regulation of innate and adaptive immunity in the intestinal tract. Science. 2005;307(5710):731-4.

42. Shin R, Suzuki M, Morishita Y. Influence of intestinal anaerobes and organic acids on the growth of enterohaemorrhagic Escherichia coli 0157:H7. J Med Microbiol. 2002;51(3):201-6.

43. Cotter PD, Hill C, Ross RP. Bacteriocins: developing innate immunity for food. Nat Rev Microbiol. 2005;3(10):777-88.

44. Mokoena MP. Lactic acid bacteria and their bacteriocins: classification, biosynthesis and applications against uropathogens: a mini-Review. Molecules. 2017:22(8):1255.

45. Porto MCW, Kuniyoshi TM, Azevedo POS, Vitolo M, Oliveira RPS Pediococcus spp.: an important genus of lactic acid bacteria and pediocin producers. Biotechnol Adv. 2017;35(3):361-74. 
46. Piper C, Cotter PD, Ross RP, Hill C. Discovery of medically significant lantibiotics. Curr Drug Discov Technol. 2009;6(1):1-18.

47. Barbour A, Wescombe P, Smith L. Evolution of lantibiotic salivaricins: new weapons to fight infectious diseases. Trends Microbiol. 2020;28(7):578-93.

48. Kobayashi N, Takahashi D, Takano S, Kimura S, Hase K. The roles of Peyer's patches and microfold cells in the gut immune system: relevance to autoimmune diseases. Front Immunol. 2019;10:2345.

49. Qi C, Sun J, Li Y, Gu M, Goulette T, You X, et al. Peyer's patch-specific Lactobacillus reuteri strains increase extracellular microbial DNA and antimicrobial peptide expression in the mouse small intestine. Food Funct. 2018;9(5):2989-97.

50. Wang P, Li Y, Xiao H, Shi Y, Le G-W, Sun J. Isolation of lactobacillus reuteri from Peyer's patches and their effects on slgA production and gut microbiota diversity. Mol Nutr Food Res. 2016;60(9):2020-30.

51. Liu N, Dong Z, Zhu X, Xu H, Zhao Z. Characterization and protective effect of Polygonatum sibiricum polysaccharide against cyclophosphamideinduced immunosuppression in Balb/c mice. Int J Biol Macromol. 2018; 107(Pt A):796-802.

52. Vujanovic NL. Role of TNF superfamily ligands in innate immunity. Immunol Res. 2011;50(2-3):159-74.

53. Scheller J, Chalaris A, Schmidt-Arras D, Rose-John S. The pro- and antiinflammatory properties of the cytokine interleukin-6. Biochim Biophys Acta. 2011;1813(5):878-88.

54. Claes IJJ, Segers ME, Verhoeven TLA, Dusselier M, Sels BF, De Keersmaecker SCJ, et al. Lipoteichoic acid is an important microbe-associated molecular pattern of Lactobacillus rhamnosus GG. Microb Cell Factories. 2012;11:161.

55. Wolf AJ, Underhill DM. Peptidoglycan recognition by the innate immune system. Nat Rev Immunol. 2018;18(4):243-54.

56. Saraiva M, O'Garra A. The regulation of IL-10 production by immune cells. Nat Rev Immunol. 2010;10(3):170-81.

57. Ryan PM, Stolte EH, London LEE, Wells JM, Long SL, Joyce SA, et al. Lactobacillus mucosae DPC 6426 as a bile-modifying and immunomodulatory microbe. BMC Microbiol. 2019;19(1):33.

58. Li L-Q, Song A-X, Yin J-Y, Siu K-C, Wong W-T, Wu J-Y. Anti-inflammation activity of exopolysaccharides produced by a medicinal fungus Cordyceps sinensis Cs-HK1 in cell and animal models. Int J Biol Macromol. 2020;149: 1042-50.

59. Weisburg WG, Barns SM, Pelletier DA, Lane DJ. 16 S ribosomal DNA amplification for phylogenetic study. J Bacteriol. 1991;173(2):697-703.

60. Jackman SD, Vandervalk BP, Mohamadi H, Chu J, Yeo S, Hammond SA, et al. ABySS 2.0: resource-efficient assembly of large genomes using a bloom filter. Genome Res. 2017;27(5):768-77.

61. Besemer J, Lomsadze A, Borodovsky M. GeneMarkS: a self-training method for prediction of gene starts in microbial genomes. Implications for finding sequence motifs in regulatory regions. Nucleic Acids Res. 2001;29(12):260718.

62. Lagesen K, Hallin P, Rødland EA, Staerfeldt H-H, Rognes T, Ussery DW. RNAmmer: consistent and rapid annotation of ribosomal RNA genes. Nucleic Acids Res. 2007;35(9):3100-8.

63. Lowe TM, Chan PP. tRNAscan-SE on-line: integrating search and context for analysis of transfer RNA genes. Nucleic Acids Res. 2016;44(W1):W54-W7.

64. O'Leary NA, Wright MW, Brister JR, Ciufo S, Haddad D, McVeigh R, et al. Reference sequence (RefSeq) database at NCBl: current status, taxonomic expansion, and functional annotation. Nucleic Acids Res. 2016;44(D1):D733-D45.

65. Galperin MY, Makarova KS, Wolf Yl, Koonin EV. Expanded microbial genome coverage and improved protein family annotation in the COG database. Nucleic Acids Res. 2015:43(Database issue):D261-D9.

66. Lombard V, Golaconda Ramulu H, Drula E, Coutinho PM, Henrissat B. The carbohydrate-active enzymes database (CAZy) in 2013. Nucleic Acids Res. 2014;42(Database issue):D490-D5.

67. Katoh K, Standley DM. MAFFT multiple sequence alignment software version 7: improvements in performance and usability. Mol Biol Evol. 2013; 30(4):772-80.

68. Price MN, Dehal PS, Arkin AP. FastTree: computing large minimum evolution trees with profiles instead of a distance matrix. Mol Biol Evol. 2009;26(7): $1641-50$.

69. Blin K, Shaw S, Steinke K, Villebro R, Ziemert N, Lee SY, et al. antiSMASH 5.0: updates to the secondary metabolite genome mining pipeline. Nucleic Acids Res. 2019;47(W1):W81-W7.

70. Elbanna K, El Hadad S, Assaeedi A, Aldahlawi A, Khider M, Alhebshi A. In vitro and in vivo evidences for innate immune stimulators lactic acid bacterial starters isolated from fermented camel dairy products. Sci Rep. 2018:8(1):12553.

71. Casey PG, Casey GD, Gardiner GE, Tangney M, Stanton C, Ross RP, et al. Isolation and characterization of anti-Salmonella lactic acid bacteria from the porcine gastrointestinal tract. Lett Appl Microbiol. 2004;39(5):431-8.

72. Zheng Z-Y, Cao F-W, Wang W-J, Yu J, Chen C, Chen B, et al. Probiotic characteristics of Lactobacillus plantarum E680 and its effect on Hypercholesterolemic mice. BMC Microbiol. 2020;20(1):239.

\section{Publisher's Note}

Springer Nature remains neutral with regard to jurisdictional claims in published maps and institutional affiliations.
Ready to submit your research? Choose BMC and benefit from:

- fast, convenient online submission

- thorough peer review by experienced researchers in your field

- rapid publication on acceptance

- support for research data, including large and complex data types

- gold Open Access which fosters wider collaboration and increased citations

- maximum visibility for your research: over $100 \mathrm{M}$ website views per year

At $\mathrm{BMC}$, research is always in progress.

Learn more biomedcentral.com/submissions 